\title{
Impacts of COVID-19 Pandemic on Air Quality Index (AQI) During Partial Lockdown in Karachi Pakistan
}

\author{
Akhtar Shareef*, Durdana Rais Hashmi \\ Centre for Environmental Studies, Pakistan Council of Scientific and Industrial Research Laboratories Complex, Karachi, Pakistan
}

Email address:

akhtarshareef@yahoo.com (A. Shareef),drhpakr@yahoo.com (D. R. Hashmi)

${ }^{*}$ Corresponding author

\section{To cite this article:}

Akhtar Shareef, Durdana Rais Hashmi. Impacts of COVID-19 Pandemic on Air Quality Index (AQI) During Partial Lockdown in Karachi Pakistan. Journal of Health and Environmental Research. Vol. 6, No. 3, 2020, pp. 93-97. doi: 10.11648/j.jher.20200603.17

Received: July 17, 2020; Accepted: July 31, 2020; Published: August 27, 2020

\begin{abstract}
A novel infectious disease (COVID-19) was identified in the late months of 2019, with human to human transmission, and rapidly spread in the world, which now has turned into a global pandemic. The coronavirus (COVID-19) is extremely threatening world public health problem. Up-till now, more than 200 countries and states had been affected by this pandemic. The number of contagions and deaths still increasing day by day. Different steps have been taken worldwide to control COVID-19. Countries all over the world have applied specific type of lockdown in order to control / slow down the intensity of infection and mitigate it. This lockdown due to COVID-19 not only smashed the economic growth but also exert a positive impact on the environment and improves the level of air quality in the city/country. This study was carried out for investigation of air quality before and during the periods of lockdown levied to reduce the spread of a novel coronavirus (COVID-19) in the environment of Karachi city. Concentrations of four pollutant parameters $\left(\mathrm{PM}_{10}, \mathrm{SO}_{2}, \mathrm{NO}_{2}\right.$ and $\mathrm{CO}$ ) were used to calculate the results according to the criteria of Air Quality Index (AQI). We have analyzed data collected from fourteen different monitoring locations along the busy roads in commercial, residential and industrial areas of Karachi during the lockdown period. Data were compared to the five-year monthly mean and to the four-week before the partial lockdown. The results proved that during lockdown air quality is significantly improved. Among the selected pollutants, concentrations of $\mathrm{PM}_{10}$ have observed maximum reduction (50\%) in comparison to the before lockdown period. In compare to the last year (i.e. 2019) during the said time period the reduction of $\mathrm{PM}_{10}$ is as high as about $60 \%$. Among other pollutants, $\mathrm{SO}_{2}, \mathrm{NO}_{2}$ and $\mathrm{CO}$ the level have also reduced about $60-70 \%$ during lockdown period. About $40 \%$ to $50 \%$ improvement in air quality is identified just after four days of commencing lockdown. Overall, the study is assumed to be a useful tool to the regulatory bodies to control the air quality and also explained its relation to health hazards to provide awareness in the society.
\end{abstract}

Keywords: Air Pollution, COVID-19, Lock Down

\section{Introduction}

The novel coronavirus is a new born virus that has never been identified before. This coronavirus is one of the main virus that target on the lungs and infected the respiratory tract or bronchial system of the human being [1]. According to the researchers in China this virus named as 2019-nCoV [2], whereas, ICT (International Committee on Taxonomy) named this as novel corona virus like (SARS-CoV-2) Severe Acute Respiratory Syndrome Coronavirus-2 (SARSCoV-2) [3]. COVID-19 is an extremely infectious disease initially identified in December 2019 [4], on January 30,
2020 WHO (World Health Organization) declared this COVID-19 outbreak as sixth public health of emergency Services (SPHEC) [5]. In Feb 2020, due to cluster of cases (COVID-19), which rapidly increase in surrounding areas, countries and in the world the outbreak turned into global epidemic [6], By March 2020 the virus has spread globally and was declared as global pandemic, (WHO) name this as acute respiratory infection lead to Pneumonia with the symptoms of high fever, dry cough and dyspnea $[7,8]$. This coronavirus reached in Pakistan in the month of February of this year, 2020. The first case of this COVID-19 disease was reported and confirmed in February 26, 2020 in 
Karachi, when a patient was admitted in the hospital with the symptoms of high fever, dry cough and respiratory tract infections [9]. It is a highly infectious and transmittable virus that transmitted through the respiratory functions, such as sneezing, coughing and respiratory droplets from infected peoples [10]. Spreading of this infection may also occur through fomites in the immediate environment around the infected person [11]. COVID-19 virus can also de spread by direct contact with infected persons and by indirect contact with surfaces in the close environment or with the objects used on the infected persons (e.g., medical instruments). All of the confirmed cases in Pakistan during February and March 2020 had recent travel history from Iran, Syria and London. Due to increased cases at high rate the situation becomes worst, As a result on $1^{\text {st }}$ April 2020, partial lockdown was ordered by the Government of Pakistan, closing transportation, shopping malls, restaurants, fitness center, elementary, middle and high schools, and universities. Groceries shops, meat seller and medical stores were working with restrictions concerning face mask, gloves, with social distancing in reduced hours. The country had been put under a nationwide lockdown until 9 May and later extended twice. The infection of this pandemic disease can be control or reduced by taking proper protective measures, frequently hand washing and social distancing. On 7 May Prime Minister of Pakistan broadcast to ease phase wise lockdown from 9 May 2020. As lockdown due to COVID-19 reduced transportation activities which lower the energy consumption and fuel / oil demand. These changes in transportation activities, energy consumption and oil demand exert a significant impact on the atmospheric pollution/environmental quality. Researchers in Pakistan say that the lockdown has an unbelievable impact on Environment. They have observed amazingly improvements in the air quality index of the city linked with social distancing measures, and decreasing use of vehicle transit. Few social media users put up pictures claim to see Kashmir from Sialkot Line of Control (LOC) in 30 years. NASA (National Aeronautics and Space Administration) and ESA (European Space Agency) released fresh reports, which suggest that environmental quality improved due to decrease in vehicular emission. The aim of this study was to assess impacts on air quality index in Karachi, during the partial lockdown period due to the global pandemic COVID-19.

\section{Material and Methods}

\subsection{Study Area}

Karachi lies between $24^{\circ} 45^{\prime} \mathrm{N}$ in longitude and $66^{\circ} 37^{\prime} \mathrm{E}$ in latitude. It has an area of $3,640 \mathrm{~km}^{2}$ and is situated along the cost of Arabian Sea. It is the largest metropolitan city of Pakistan. Karachi has a moderately temperate climate with a generally high relative humidity. In winter, the average temperature of the city is about $21^{\circ} \mathrm{C}$ while in summer it reaches up to $35^{\circ} \mathrm{C}$. Karachi receives about $256 \mathrm{~mm}$ of average annual rainfall [12]. Vehicular emission, biomass burning for cooking and brick kilns and industrial emissions around the Karachi city are the main contributor of atmospheric pollution in Karachi.

\subsection{Ambient Air Monitoring}

\subsubsection{Sampling}

Sampling was carried out at fourteen different locations along the busy roads of Karachi used to assess the levels of particulate matter $\left(\mathrm{PM}_{10}\right)$ with a diameter of less than $10 \mu \mathrm{m}$, Carbon monoxide (CO), Nitrogen oxides (NOx) and Sulphur dioxide $\left(\mathrm{SO}_{2}\right)$. At each location, monthly data $(8 \mathrm{~h})$ from February, March, and April of the years 2015, 2016, 2017, 2018 and 2019 were used to calculate the mean levels of each pollutant to estimate a five-year monthly trend. Similarly, data from February 25, 2020 to March 23, 2020 (four-week before partial lockdown) and from March 24, 2020 to April 20, 2020 (four-week during partial lock-down) were used to analyze the mean levels of each pollutant. Similarly, the variations in AQI concentrations ( $\mu \mathrm{g} / \mathrm{m}^{3}, \mathrm{ppb}$ or $\left.\mathrm{ppm}\right)$ were calculated to assess comparing the partial lockdown period to the five-year monthly trend or to the four-week before partial lockdown.

Monitoring of gaseous pollutants were carried out by UV Fluorescent $\mathrm{SO}_{2}$ Analyzer Model AF22 M, NO-NOx Analyzer Model AC 32M and Snifit CO Analyzer (Model 50). These analyzers are considered as reliable for monitoring the pollution level.

$\mathrm{PM}_{10}$ samples were carried out by using glass fiber filters $(203 \times 254 \mathrm{~mm})$ in high volume air sampler with an average flow rate of $1.0 \mathrm{~m}^{3} / \mathrm{min}$. Eight hour sampling was done in duplicate at each location during the year 2016. The high volume is considered a reliable instrument for measuring the weight of $\mathrm{PM}_{10}$ in ambient air (USEPA-Method 40 CFR).

The locations were chosen to reflect the influences from residential, commercial, industrial areas regarding the low, moderate and heavy traffic sources. This was done with an intention to get better representation of the city. Eight hour sampling / monitoring was done in duplicate at each location during the year 2015 - 2019.

\subsubsection{Air Quality Index (AQI)}

In this study, AQI was calculated with reference to the concentration of pollution proposed by US-EPA (US-EPA, 2012). These AQI values predict, evaluate and explained the air quality status and health concerns at the selected sites. As the air pollution increases, adverse health effect also increases.

Table 1 shows the air quality index with the category of health risk. The air quality index of zero to fifty is good for human health and indicates clean air, 50 to 100 indicates moderate air quality, 101 to 150 points toward unhealthy for sensitive group, 151 to 200 express unhealthy for all people, 200 to 300 very unhealthy, 301 to 500 hazardous and $>500$ indicates sever hazardous (Table 1). 
Table 1. AQI Criteria and Quality Category.

\begin{tabular}{|c|c|c|c|}
\hline $\mathbf{A Q I}$ & AQI Category & Colour Show the Category & Health Impact \\
\hline $0-50$ & Good & Green & Air quality is considered satisfactory with little or no risk of air pollution. \\
\hline $51-100$ & Moderate & Yellow & $\begin{array}{l}\text { Air quality is acceptable though pollution level makes concern for a group } \\
\text { of people who are sensitive to air pollution. }\end{array}$ \\
\hline $101-150$ & Unhealthy for Sensitive & Orange & $\begin{array}{l}\text { Members of sensitive groups may have health effects, and the general } \\
\text { public is not likely to be affected. }\end{array}$ \\
\hline $151-200$ & Poor / Unhealthy & Red & $\begin{array}{l}\text { Everyone may experience health hazards, and sensitive peoples may } \\
\text { experience more serious health effects. }\end{array}$ \\
\hline $201-300$ & Very poor / very unhealthy & Purple & The entire population may experience more serious health effects. \\
\hline $301-500$ & Hazardous & Mahroon & Everyone is likely to be affected by more serious health effects. \\
\hline
\end{tabular}

Source: [13, 14].

\section{Results and Discussion}

Present study was carried out to estimate the concentrations of ambient air pollution with $\mathrm{PM}_{10}$ size fractions by using Air Quality Index (AQI) at fourteen different locations in Karachi. Researchers in Pakistan say that the lockdown has an unbelievable impact on Environment. They have observed amazingly improvements in the air quality index of the city linked with social distancing measures, and decreasing use of vehicle transit. Similarly different countries have also stated remarkable air quality improvements associated with lockdown situation. For example, in China the researchers estimate the concentration of particulate matter $\left(\mathrm{PM}_{2.5}\right)$ by using the Copernicus Atmosphere Monitoring Service and observed approximately $20-30 \%$ reduction in February 2020 (monthaly average) in comparison to monthly averages of February 2017, 2018 and 2019 [15]. In Barcelona (Spain) the researchers estimate the concentration of particulate matter $\left(\mathrm{PM}_{10}\right)$ and nitrogen dioxide $\left(\mathrm{NO}_{2}\right)$ by using the Copernicus Tropospheric Monitoring Instrument and data collected from one traffic station observed $31 \%$ and $51 \%$ reduction in $\mathrm{PM}_{10}$ and $\mathrm{NO}_{2}$ respectively, during and before the lockdown period [16]. In India researchers assess the effects of lockdown on air quality and perceived $43 \%$ and $31 \%$ reduction of particulate matter $\left(\mathrm{PM}_{2.5}\right)$ and particulate matter $\left(\mathrm{PM}_{10}\right)$, respectively, during the lockdown compared to the same time period of the past four years [17]. Researchers and Experts in Pakistan also believe that the temporary break to the daily lives following the nationwide lockdown has improved the air quality Index. Evaluation of the concentrations of ambient $\mathrm{PM}_{10}$ and trace gases, $\left(\mathrm{SO}_{2}, \mathrm{NO}_{2}\right.$ and $\left.\mathrm{CO}\right)$ were determined on the basis of $\mathrm{PM}_{10}$ size fractions at the selected locations in Karachi before and during lockdown period.

Five years AQI means of pollutants during 2015 - 2019 presented in Table 2 shows that, the average concentrations of $\mathrm{PM}_{10}$ were higher in commercial and industrial areas with high traffic density than the residential areas. In most of the areas $\mathrm{PM}_{10}$ concentrations exceeded the specified permissible limits by US-EPA (US-EPA, 2012). The highest mean concentration of $\mathrm{NOx}$ and $\mathrm{PM}_{10}$ were observed in commercial and industrial areas having industrial clusters on both sides of the way, also having high traffic congestion due to heavy duty diesel vehicles like, tractors, trucks, trailers, vans, buses and minibuses. Similarly the roads are also poorly maintained, unpaved and dusty with limited vegetation along the sides. The industrial processes especially combustion boilers fueled by heavy duty diesel, and heavy electric generators also fueled by diesel are the main source of $\mathrm{NO}_{\mathrm{X}}$ and $\mathrm{PM}_{10}$ pollution, Whereas, commercial areas having narrow road with heavy traffic density and surrounded by high rise buildings for commercial activities on both side of the road producing tunnel effect where the pollutants are suspended for long time and it is associated with potential health effects for the resident specially for infant and old age group/sensitive residents.

Due to the contagion of COVID-19, a nationwide lockdown was imposed. By this nationwide lockdown almost all industrial activities and mass transportation had been prohibited. As a result, the pollution level in all the cities across the country drastically reduced down. In the commercial and industrial areas we observed significant air quality improvements considering decreases in air pollutants monitored in the selected areas highly influenced by vehicular traffic (Table 2). Mostly Good and Moderate AQI level of pollutants were found during partial lockdown period (25 March - 20 April, 2020) compared to the five-year monthly mean, while significant reductions were found in comparison to the period before partial lockdown period (10 Jan - 10 Feb, 2020) Poor and unhealthy AQI of air pollutants concentration compared to the five-year monthly mean. Drastic reductions on $\mathrm{PM}_{10}, \mathrm{CO}, \mathrm{SO}_{2}$ and $\mathrm{NOx}$ concentrations were observed in all the selected area during partial lockdown compared to the five-year monthly mean. One recent research has demonstrated that traffic emissions from heavy-duty diesel trucks are major sources of NO [18], during the partial lockdown, vehicle traffic considerably decreased in all analyzed areas, positively affecting the air quality. Therefore lockdown presumes to be the effective alternative measure to be implemented for controlling air pollution and the present work intended to explore the degree of air quality change during lockdown at spatial scale in the megacity Karachi. 
Table 2. Mean AQI mean of $\mathrm{CO}, \mathrm{SO}_{2}, \mathrm{NOx}$ and $\mathrm{PM}_{10}$ in Karachi, Pakistan. Five-year monthly mean (2015-2019) and mean of two week before partial Lockdown (January 10 to February 10, 2020) and two week during partial lockdown (March 25, 2020 to April 20, 2020).

\begin{tabular}{|c|c|c|c|c|c|}
\hline \multirow{3}{*}{ Locations / Air Pollutant } & \multirow{2}{*}{\multicolumn{3}{|c|}{$\begin{array}{l}\text { Five year AQI mean } \\
(2015-2019)\end{array}$}} & \multirow{3}{*}{$\begin{array}{l}\text { AQI Mean four week before } \\
\text { lock down } \\
10 \text { Jan - } 10 \text { Feb, } 2020 \\
\end{array}$} & \multirow{3}{*}{$\begin{array}{l}\begin{array}{l}\text { AQI Mean four week } \\
\text { during lock down }\end{array} \\
25 \text { March - } 20 \text { April, 2020 } \\
\end{array}$} \\
\hline & & & & & \\
\hline & Feb & March & April & & \\
\hline \multicolumn{6}{|l|}{ Industrial Areas } \\
\hline $\mathrm{PM}_{10}$ & Poor & Unhealthy & Poor & Poor & Moderate \\
\hline NOx & Unhealthy & Unhealthy & Unhealthy & Unhealthy & Moderate \\
\hline $\mathrm{CO}$ & Good & Moderate & Moderate & Good & Good \\
\hline $\mathrm{SO}_{2}$ & Moderate & Good & Moderate & Moderate & Good \\
\hline \multicolumn{6}{|l|}{ Residential Areas } \\
\hline $\mathrm{PM}_{10}$ & Moderate & Unhealthy & Unhealthy & Unhealthy & Good \\
\hline NOx & Moderate & Moderate & Good & Unhealthy & Good \\
\hline $\mathrm{CO}$ & Good & Good & Moderate & Good & Good \\
\hline $\mathrm{SO}_{2}$ & Good & Moderate & Moderate & Moderate & Good \\
\hline \multicolumn{6}{|l|}{ Commercial Areas } \\
\hline $\mathrm{PM}_{10}$ & Poor & Moderate & Poor & Poor & Moderate \\
\hline NOx & Poor & Unhealthy & Unhealthy & Unhealthy & Good \\
\hline $\mathrm{CO}$ & Moderate & Moderate & Moderate & Good & Good \\
\hline $\mathrm{SO}_{2}$ & Moderate & Unhealthy & Moderate & Moderate & Good \\
\hline
\end{tabular}

\section{Conclusions}

The study is thought to be a useful complement to the regulatory authorities that may lead to re-thinking of the existing regulatory plans and may provide pledge towards implementing strict alternative measures like short term $(2$ to 4 day) lockdown in purpose to control air quality. To facilitate fruitful implementation of this type of measures once or twice a year in a long-distance race in-depth analysis of the seasonal change in air quality in relation to regional meteorological condition is also required to be studied.

\section{References}

[1] S. Hoehl, H. Rabenau, A. Berger, M. Kortenbusch, J. Cinatl, D. Bojkova, P. Neumann. "Evidence of SARS-CoV-2 infection in returning travelers from wuhan, China", New England J Med., vol. 382 (13), pp. 1278-1280, 2020.

[2] N. Zhu, D. Zhang, W. Wang, X. Li, B. Yang, J. Song, P. Niu. "A novel coronavirus from patients with pneumonia in China, 2019”, New England J Med., vol. 382 (8), pp. 727, 2020.

[3] Z. Y. Zu, M. D. Jiang, P. P. Xu, W. Chen, Q. Q. Ni, G. M. Lu, L. J. Zhang. "Coronavirus disease 2019 (COVID-19): a perspective from China”, Radiology, pp. 200490, 2020.

[4] H. Chen, J. Guo, C. Wang, F. Luo, X. Yu, W. Zhang, J. Li, D. Zhao, D. Xu, Q. Gong, J. Liao, H. Yang, W. Hou, Y. Zhang, "Clinical characteristics and intrauterine vertical transmission potential of COVID-19 infection in nine pregnant women: a retrospective review of medical records" The lancet, vol. 395, pp. 809-815, 2020.

[5] S. Bilgin, O. Kurtkulagi, G. B. Kahveci, T. T. Duman, "Millennium pandemic: a review of coronavirus disease (COVID-19)", Exp Biomed Res., vol. 3 (2), pp. 117-125, 2020 .

[6] F. Dutheil, S. J. Baker, V. Navel, "COVID-19 as a factor influencing air pollution?”, Environ. Pollut. pp. 114466, 2020.
[7] F. Jiang, L. Deng, L. Zhang, Y. Cai, C. W. Cheung, Z. Xia, "Review of the clinical characteristics of coronavirus disease 2019 (COVID-19)", J. Gen. Intern. Med., pp. 11606-020, 2020.

[8] A. J. Rodriguez-Morales, R. Tiwari, R. Sah, K. Dhama, "COVID-19, an emerging coronavirus infection: current scenario and recent developments an overview", J. Pure Appl. Microbiol., vol. 14 (1), pp. 5-12, 2020.

[9] M. Saqlain, M. M. Munir, A. Ahmed, A. H. Tahir, S. Kamran, "Is Pakistan prepared to tackle the coronavirus epidemic?", Drugs Ther Perspect, vol. 36, pp. 213-214, March 2020.

[10] J. V. Wang, L. C. Parish, "Dermatologic Manifestations of the 1918-1919 Influenza Pandemic" Skinmed, vol. 17 (5), pp. 296-297, 2019.

[11] S. W. Ong, Y. K. Tan, P. Y. Chia, T. H. Lee, O. T. Ng, M. S. Wong, et al., "Air, surface environmental, and personal protective equipment contamination by severe acute respiratory syndrome coronavirus 2 (SARS-CoV-2) from a symptomatic patient", JAMA, vol. 323 (16), pp. 1610-1612, March 2020.

[12] S. H. Sajjad, N. Blond, A. Clapper, R. Asif, "Preliminary Study of Urbanization, Fossil fuels consumptions and $\mathrm{CO} 2$ emission in Karachi", Afric. J. of Biotechnol., vol. 9 (13), pp. 1941-1948, 2010.

[13] U.S. EPA (2012), revised air quality standards for particle pollution and updates to the Air Quality Index (AQI). Office of Air Quality Planning and Standards, EPA 454/R99-010.

[14] B. R. Gurjar, T. M. Butler, M. G. Lawrence, J. Lelieveld, "Evaluation of Emissions and Air Quality in Megacities", Atmospheric Environment, vol. 42, pp. 1593-1606, 2008.

[15] M. A. Zambrano-Monserrate, M. A. Ruano,, L. SanchezAlcalde, "Indirect effects of COVID-19 on the environment", Sci. Total Environ., vol. 728, pp. 138813, 2020.

[16] A. Tobías, C. Carnerero, C. Reche, J. Massagué, M. Via, M. C. Minguillón, A. Alastuey, X. Querol, "Changes in air quality during the lockdown in Barcelona (Spain) one month into the SARS-CoV-2 epidemic" Sci. Total Environ., vol. 726, pp. 138540, July 2020. 
[17] S. Sharma, M. Zhang, J. Anshika Gao, H. Zhang, S. H. Kota, "Effect of restricted emissions during COVID-19 on air quality in India" Sci. Total Environ., vol. 728, pp. 138878, 2020 .
[18] L. He, S. Zhang, J. Hu, Z. Li, X. Zheng, Y. Cao, G. Xu, M. Yan, Y. Wu, "On-road emission measurements of reactive nitrogen compounds from heavy-duty diesel trucks in China" Environ. Pollut. vol. 262, pp. 114280, 2020. 